\title{
Characterization of a haemolytic factor from Candida albicans
}

\author{
Toshihiko Watanabe, ${ }^{1}$ Mari Takano, ${ }^{1}$ Mariko Murakami,, \\ Hironori Tanaka, ${ }^{1}$ Atsushi Matsuhisa, ${ }^{1}$ Noriko Nakao, ${ }^{1}$ \\ Takeshi Mikami, ${ }^{1}$ Masuko Suzuki ${ }^{2}$ and Tatsuji Matsumoto ${ }^{1}$
}

Author for correspondence: Tatsuji Matsumoto. Tel: +8122 234 4181. Fax: +81222752013.

e-mail: tmatsu@tohoku-pharm.ac.jp

1 Department of Microbiology, Tohoku College of Pharmacy, 4-1 Komatsushima 4 Chome, Aoba-ku, Sendai 981-8558, Japan

2 Sendai Research Institute for Mycology, 14-34 Toshogu 1 Chome, Aobaku, Sendai 981-0908, Japan

\begin{abstract}
The culture supernatant of Candida albicans promoted the disruption of human red blood cells (RBCs). The haemolytic activity was detected in a sugarrich fraction (about $200 \mathrm{kDa}$ ) from Sephacryl S-100 chromatography. As the haemolytic activity was adsorbed by concanavalin A-Sepharose, the haemolytic factor may be a mannoprotein. The activity was inactivated by periodate oxidation, indicating that the sugar moiety of the mannoprotein played an important role in the haemolysis. The structure of the sugar moiety of the mannoprotein was identified as a cell-wall mannan by ${ }^{1} \mathrm{H}-\mathrm{NMR}$ analysis, and purified C. albicans mannan promoted the disruption of RBCs. The binding of mannan to RBCs was demonstrated by flow cytometric analysis and was inhibited by the addition of band 3 protein inhibitor, 4,4'-diisothiocyanatostilbene-2,2'-disulfonic acid (DIDS). The haemolysis caused by mannan was inhibited by DIDS, SITS (4-acetamido-4'-isothiocyanatostilbene2,2'-disulfonic acid) and bis(sulfosuccinimidyl) suberate, but not by pyridoxal 5-phosphate. These results indicated that a mannoprotein released from $C$. albicans bound to the band 3 protein on RBCs, thereby promoting their disruption.
\end{abstract}

Keywords: Candida albicans, mannan, band 3 protein, haemolysis

\section{INTRODUCTION}

The opportunistic pathogen Candida albicans is a serious agent of infection in the immunocompromised host. C. albicans is a dimorphic fungus which can alternate between yeast and hyphal phases, depending on the growth conditions (Blasi et al., 1994). The cell wall of C. albicans contains a mannan which has a linear $1,6-\alpha$-linked mannose backbone with side chains of 1,2$\alpha-, 1,2-\beta$ - and 1,3- $\alpha$-linked mannose units (Shibata et al., 1995). The antigenicity of Candida species depends on the structure of their mannans, and differences of antigenicity in mannans are used in the classification of Candida species (Ataoglu et al., 1993; Kobayashi et al., 1992). C. albicans possesses a number of factors that could be involved in the invasive process. Adhesins,

Abbreviations: $\mathrm{BS}^{3}$, bis(sulfosuccinimidyl) suberate; ConA, concanavalin A; DIDS, 4,4'-diisothiocyanatostilbene-2,2'-disulfonic acid; FAb 1, antiserum against factor 1 of the genus Candida; PBS(-), $\mathrm{Ca}^{2+}$ - and $\mathrm{Mg}^{2+}$-free PBS; PLP, pyridoxal 5-phosphate; RBC, red blood cell; SITS, 4-acetamido-4'isothiocyanatostilbene-2,2'-disulfonic acid. dimorphism and the secretion of specific hydrolytic enzymes have been suggested as possible virulence factors (Cameron \& Douglas, 1996; Colina et al., 1996; Ibrahim et al., 1995).

Adherence to endothelial cells by C. albicans is mediated by a glycoprotein which is known to bind fibronectin; adherence is blocked by a peptide containing an ArgGly-Asp sequence (Pendrak \& Klotz, 1995; Sawyer et al., 1992). When C. albicans is phagocytosed by endothelial cells, it converts to the hyphal form and damages the endothelial cells (Zink et al., 1996). Hydrolytic enzymes such as proteases and phospholipases are known to promote invasiveness in disseminated candidiasis (Fallon et al., 1997). Numerous pathogenic micro-organisms grow in the host by using haemin or haemoglobin as a source of iron (Henderson \& Payne, 1994; Law \& Kelly, 1995; Otto et al., 1992). We previously reported that $C$. albicans secretes a haemolytic factor that causes the release of haemoglobin, which is then used as an iron source by the organisms (Watanabe et al., 1997), but the haemolytic 


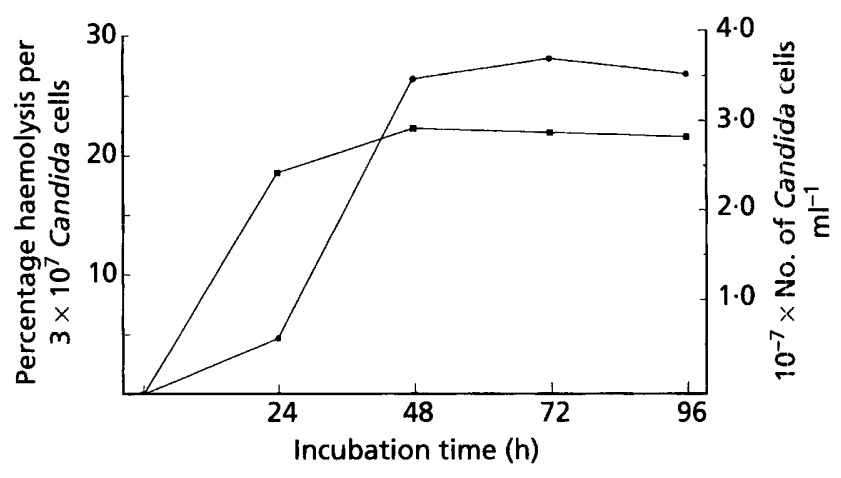

Fig. 1. Haemolytic activity in C. albicans culture supernatant. $C$. albicans cells were cultured in RPMI 1640 medium $\left(1 \times 10^{4}\right.$ cells $\mathrm{ml}^{-1}$ ) at $37^{\circ} \mathrm{C}$ in $5 \% \mathrm{CO}_{2}$. The culture supernatant was collected daily and mixed with RBCs $\left(1 \times 10^{8}\right.$ cells $\left.\mathrm{ml}^{-1}\right)$ at a $1: 1$ ratio, and incubated at $37^{\circ} \mathrm{C}$ for $12 \mathrm{~h}$. After incubation, the $A_{405}$ of the supernatant was measured to estimate the degree of disruption of the RBC (O). The percentage haemolysis was determined by comparing the $A_{405}$ resulting from incubation with the test sample with that resulting from $100 \%$ lysis with water. The growth of $C$. albicans was measured by the Alamar blue method and the number of cells was measured as the $O D_{540}$ minus $\mathrm{OD}_{620}(\mathbf{\square})$.

factor was not identified. In this study, we have characterized the haemolytic factor in the culture supernatant of C. albicans.

\section{METHODS}

Reagents. Concanavalin A (Con A)-Sepharose (Pharmacia), Alamar blue (Alamar Biosciences), DIDS (4,4'-diisothiocyanatostilbene-2,2'-disulfonic acid; Sigma), SITS (4acetamido-4' -isothiocyanatostilbene-2,2'-disulfonic acid; Sigma), $\mathrm{BS}^{3}$ [bis(sulfosuccinimidyl) suberate; Pierce], and PL.P (pyridoxal 5-phosphate; Nacalai Tesque) were used in the experiments. Antiserum against factor 1 of the genus Candida (FAb 1) was supplied with Candida Check kits (Iatron). Con A was purchased from Sigma, and Pepstatin A, an aspartyl protease inhibitor, was obtained from Peptide Institute.

Preparation of red blood cells (RBCs). Human RBCs (A type), supplied by the Red Cross Blood Center of Miyagi Prefecture, Japan, were suspended in $\mathrm{Ca}^{2+}$ - and $\mathrm{Mg}^{2+}$-free PBS $[\mathrm{PBS}(-)]$ and centrifuged at $700 \mathrm{~g}$ for $5 \mathrm{~min}$. The supernatant and buffy coat were removed, and the packed RBCs were further washed with PBS $(-)$ by centrifugation. RBCs were then suspended in RPMI 1640 medium and used for the haemolytic activity assay.

Preparation of $\mathrm{C}$. albicans culture supernatants. C. albicans NIH A-207 cells were maintained in Sabouraud's liquid medium with shaking at $27^{\circ} \mathrm{C}$. The cells were transferred into RPMI 1640 medium $\left(1 \times 10^{4} \mathrm{cells} \mathrm{ml}^{-1}\right)$ and incubated at $37^{\circ} \mathrm{C}$ for $4 \mathrm{~d}$. The culture supernatant was collected, dialysed and freeze-dried, and then used as the concentrated C. albicans culture supernatant. The growth of C. albicans was measured by using the Alamar blue method (Pfaller et al., 1994).

Haemolytic activity assay. Haemolytic activity was measured according to the method of Manns et al. (1994). Briefly, a sample solution was mixed with RBC $\left(1 \times 10^{8}\right.$ cells ml $\left.{ }^{-1}\right)$ at a $1: 1$ ratio and incubated at $37^{\circ} \mathrm{C}$ for $12 \mathrm{~h}$. After incubation, the $A_{405}$ in the supernatant was measured to estimate the degree of RBC disruption. The percentage haemolysis was determined by comparing the $A_{405}$ of the test group with that of $100 \%$ lysis obtained with water. To confirm the relationship of C. albicans secreted aspartyl protease with haemolysis, pepstatin $\mathrm{A}\left(0.1 \mathrm{mg} \mathrm{ml}^{-1}\right)$ was added to the mixture of the C. albicans culture supernatant and RBCs.

Purification of the haemolytic factor. The concentrated $C$. albicans culture supernatant was gel filtered through a HiPrep $16 / 60$ Sephacryl S-100 column (Pharmacia) at $1 \mathrm{ml} \mathrm{min}^{-1}$ in PBS $(-)$, and fractions of $4 \mathrm{ml}$ were collected. Total protein content was measured using a BCA protein assay kit (Pierce) with BSA as the standard. Total carbohydrate content was determined by the phenol $/ \mathrm{H}_{2} \mathrm{SO}_{4}$ method (Shibata et al., 1989) with D-mannose as the standard. To detect the fraction containing mannan, an aliquot from each fraction was added to a well of a 96-well plastic plate coated with Con A, and the amount of mannan bound to the plate was measured using an ELISA, as described previously (Mikami et al., 1986). FAb 1 and horseradish peroxidase-conjugated anti-rabbit IgG (Seikagaku) were used for the detection of mannan.

Adsorption of the haemolytic factor by Con A-Sepharose. The haemolytic fractions eluted from the HiPrep 16/60 Sephacryl S-100 column (around $200 \mathrm{kDa}$ ) were adsorbed to Con A-Sepharose by a batch affinity method at $37^{\circ} \mathrm{C}$ for $1 \mathrm{~h}$. After adsorption, the haemolytic activity and the sugar content were measured as described above.

Periodate oxidation of the haemolytic factor. The haemolytic factor bound to Con A-Sepharose was eluted with $0.2 \mathrm{M} \alpha$ methyl mannoside. The eluate was dialysed, freeze-dried and then treated with periodate oxidate, as described previously (Suzuki et al., 1977). After treatment, the sample was passed through a PD-10 (Pharmacia) column to remove the buffer salts.

${ }^{1} \mathrm{H}$-NMR spectra of mannoproteins in the $\mathrm{C}$. albicans culture supernatant. The haemolytic fraction purified using the HiPrep 16/60 Sephacryl S-100 column was dialysed and freezedried. The ${ }^{1} \mathrm{H}-\mathrm{NMR}$ spectrum of this sample was recorded using a JEOL JNM-GSX 400 spectrometer operating at $400 \mathrm{MHz}$ and a probe temperature of $45^{\circ} \mathrm{C}$. The sample was dissolved in $\mathrm{D}_{2} \mathrm{O}$, and acetone was used as the internal standard (2.217 p.p.m.).

Mannan extraction from the $C$. albicans cell wall. Mannan was prepared as described by Tojo et al. (1991) using Fehling solution. An aqueous solution of each bulk mannan preparation was applied to a column of DEAE-Sephadex A-50 (Pharmacia), and the $0.05 \mathrm{M} \mathrm{NaCl}$-eluted fraction was dialysed and then freeze-dried.

Flow cytometric analysis. RBCs $\left(1 \times 10^{6}\right.$ cells $)$ and mannan $(10 \mu \mathrm{g})$ were incubated in an ice bath for $30 \mathrm{~min}$, and the cells were then washed by centrifugation. The washed cells were treated with FAb $1(10 \mu \mathrm{l})$, and then mixed with FITC-labelled anti-rabbit IgG antibody (Seikagaku). The fluorescence intensity of individual cells was measured using a FACScan analyser (Becton Dickinson). To confirm whether band 3 protein was associated with the mannan-binding to RBCs, $\mathrm{RBCs}$ were pretreated with a band 3 protein inhibitor, DIDS $\left(0 \cdot 1 \mathrm{mg} \mathrm{ml}^{-1}\right)$, in an ice bath for $30 \mathrm{~min}$.

Extraction and purification of band 3 protein. This was done by a modification of the method of England et al. (1980).

Effects of band 3 protein inhibitors on haemolytic activity of mannan. To determine the mannan binding site on band 3 protein, RBCs were pretreated with four protein inhibitors: 

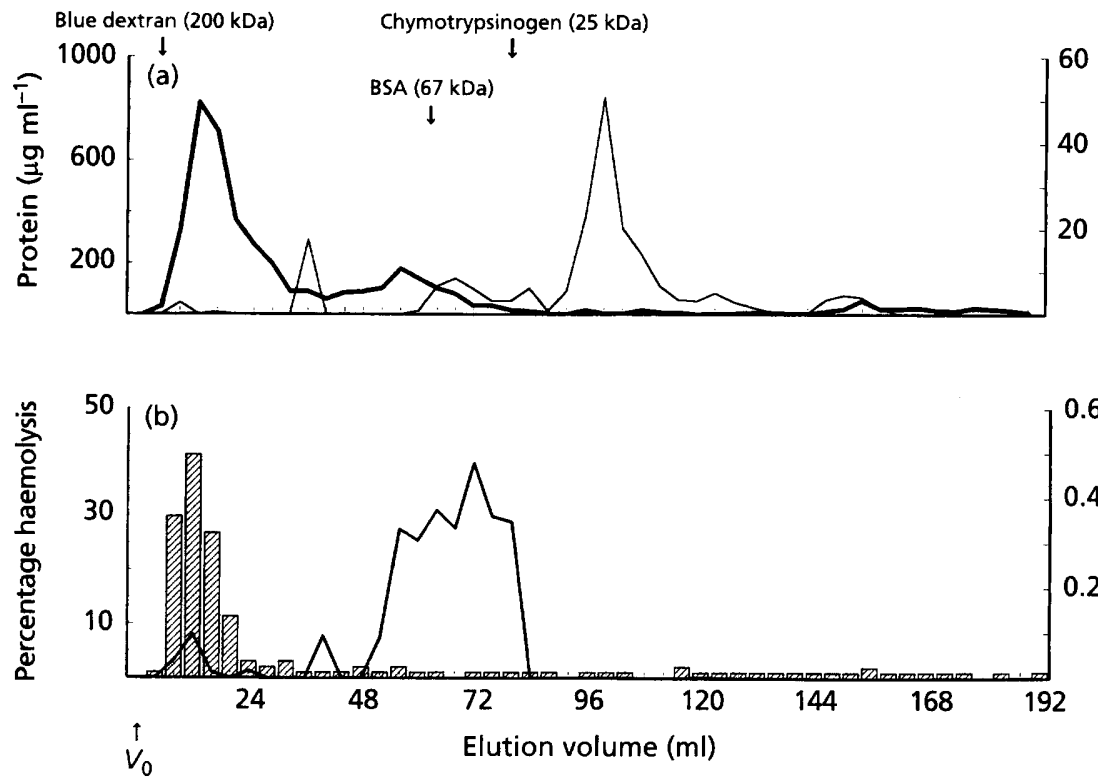

DIDS, SITS, BS ${ }^{3}$ and PLP, for $30 \mathrm{~min}$. Mannan $\left(0.5 \mathrm{mg} \mathrm{ml}^{-1}\right)$ was added to these treated cells, and the degree of haemolysis was measured.

Statistical analysis. Values are shown as means $\pm \mathrm{SE}$, and statistical analyses of these data were performed using the Student's $t$-test.

\section{RESULTS}

\section{Haemolytic activity in the C. albicans culture supernatant}

To confirm the secretion of a haemolytic factor by $C$. albicans, the culture supernatant was mixed with human RBCs, and the degree of haemolysis was examined. The haemolytic factor was secreted after $2 \mathrm{~d}$ incubation, and the activity was $27 \cdot 8 \%$ haemolysis per $3 \times 10^{7}$ Candida cells (Fig. 1). Since the haemolytic activity was not inhibited by heat treatment $\left(100{ }^{\circ} \mathrm{C}\right.$ for $\left.10 \mathrm{~min}\right)$ or by the addition of pepstatin A (an aspartyl protease inhibitor), the active component is probably not a protein such as a secreted aspartyl proteinase (data not shown).

\section{Purification of a haemolytic factor from the C. albicans culture supernatant}

The concentrated culture supernatant of C. albicans (10 mg dry wt) was gel filtered on a HiPrep $16 / 60$ Sephacryl S-100 column. Haemolytic activity $(39 \%$ haemolysis per $50 \mu \mathrm{g}$ sugar) was detected in the sugarrich fraction of $200 \mathrm{kDa}$; this fraction also reacted with FAb 1 (Fig. 2). The haemolytic fractions were pooled and fractionated on Con A-Sepharose. The haemolytic activity was associated with the material adsorbed by Con A-Sepharose and was not detected in the unbound fraction. These results indicated that a mannoprotein secreted from $C$. albicans promoted the disruption of RBCs. The haemolytic activity of the mannoprotein eluted from Con A-Sepharose $(42 \cdot 7 \%$ haemolysis per
$50 \mu \mathrm{g}$ sugar) was completely abolished by periodate oxidation, suggesting that the sugar moiety of the mannoprotein was important in inducing the haemolysis.

\section{${ }^{1} \mathrm{H}-\mathrm{NMR}$ spectrum of the mannoprotein}

The polysaccharide in the haemolytic fraction eluted from the HiPrep 16/60 Sephacryl S-100 column was structurally analysed by ${ }^{1} \mathrm{H}-\mathrm{NMR}$ spectroscopy. The anomeric proton chemical shifts of oligosaccharides were assigned by adapting the findings of Shibata $\mathrm{et}$ al. $(1993,1995)$. The polysaccharide showed signals at 4.84 and 4.85 p.p.m. (corresponding to the 1,2- $\beta$-linked mannopyranose unit), and also signals corresponding to $1,3-\alpha$ - or $1,2-\alpha$-linked mannose units $(5 \cdot 38,5 \cdot 27,5 \cdot 14$, 5.03 and 4.91 p.p.m.). These results indicated that the haemolytic polysaccharide was a mannan derived from the cell wall of C. albicans.

\section{Haemolytic activity of mannan extracted from $C$. albicans}

To confirm the role of mannan in haemolysis, we purified a C. albicans mannan (95\% carbohydrate, $3 \%$ protein). Mannose and Dextran T-40 (Pharmacia) were used as negative controls to demonstrate that the haemolysis was not due to osmolysis or non-specific activities of polysaccharides. It was found that the extent of RBC haemolysis was dependent upon the amount of mannan (Fig. 3). The addition of mannose or dextran, however, did not induce haemolysis.

\section{Mannan binding to the surface of RBCs}

We conducted flow cytometric analysis to demonstrate the existence of a mannan-binding site on RBCs. As shown in Fig. 4, the fluorescence intensity of mannan- 


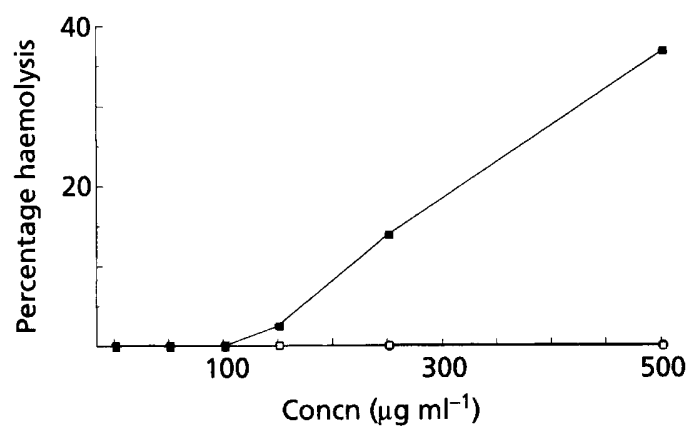

Fig. 3. Haemolytic activity of mannan extracted from $C$. albicans. The cell-wall mannan ( $\square$ ) was dissolved in RPMI 1640, and mixed with $\mathrm{RBCs}\left(1 \times 10^{8}\right.$ cells $\left.\mathrm{ml}^{-1}\right)$ at a $1: 1$ ratio. After $12 \mathrm{~h}$ incubation, the $A_{405}$ in the supernatant was measured to estimate the degree of disruption of the RBCs. The percentage haemolysis was determined by comparing the $A_{405}$ resulting from incubation with the test sample with that resulting from $100 \%$ lysis with water. Mannose $(\square)$ and dextran (O) were used as negative controls.

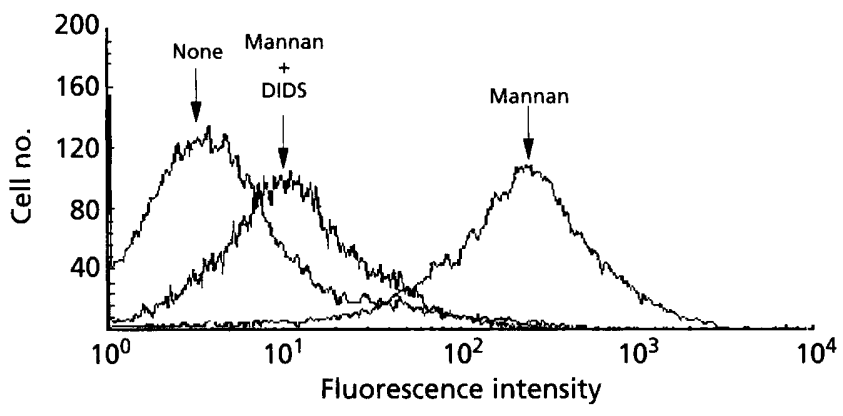

Fig. 4. Measurement of mannan binding to RBCs by flow cytometry. RBCs $\left(1 \times 10^{6}\right.$ cells) and mannan $(10 \mu \mathrm{g})$ were incubated in an ice bath for $30 \mathrm{~min}$, and the cells were washed by centrifugation. The washed cells were treated with FAb 1 $(10 \mu \mathrm{l})$, and then incubated with FITC-labelled anti-rabbit IgG antibody. The fluorescence intensity of each cell was measured using a FACScan analyser. None, RBCs only; Mannan, RBCs treated with mannan; Mannan + DIDS, RBCs pre-treated with DIDS in an ice bath for $\mathbf{3 0}$ min prior to the addition of mannarn.

treated RBCs was significantly enhanced compared with that of RBCs not treated with mannan. The binding of mannan to RBCs was strongly inhibited by the treatment of cells with $0.1 \mathrm{mg} \mathrm{m}^{-1}$ DIDS, an anion-transport inhibitor which specifically binds to a transmembrane protein, in this case, band 3 protein. This suggested that the mannan binds to the band 3 protein of RBCs.

\section{Effect of anion transport inhibitors on haemolytic activity of mannan}

The effect of DIDS on the haemolytic activity of mannan was measured to confirm the relationship between the binding of mannan to band 3 protein and haemolysis.
Table 1. Effects of anion transport inhibitors on the haemolytic activity of mannan

\begin{tabular}{|lcc|}
\hline Inhibitor & Concn $(\mathbf{m M})$ & Inhibition $(\%)^{*}$ \\
\hline \multirow{2}{*}{ DIDS } & $0 \cdot 10$ & $86 \cdot 0 \pm 2 \cdot 2$ \\
& $0 \cdot 01$ & $37 \cdot 4 \pm 5 \cdot 3$ \\
\multirow{3}{*}{ SITS } & $0 \cdot 001$ & $5 \cdot 2 \pm 3 \cdot 0$ \\
& $0 \cdot 50$ & $91 \cdot 8 \pm 1 \cdot 0$ \\
& $0 \cdot 10$ & $37 \cdot 8 \pm 1 \cdot 0$ \\
BS $^{3}$ & $0 \cdot 01$ & $20 \cdot 0 \pm 2 \cdot 0$ \\
& $4 \cdot 00$ & $78 \cdot 5 \pm 0 \cdot 6$ \\
& $2 \cdot 00$ & $61 \cdot 1 \pm 0 \cdot 4$ \\
PLP† & $1 \cdot 00$ & $27 \cdot 3 \pm 0 \cdot 9$ \\
& $0 \cdot 25$ & $0 \cdot 4 \pm 0 \cdot 1$ \\
& $0 \cdot 10$ & $0 \cdot 2 \pm 0 \cdot 1$ \\
\hline
\end{tabular}

*Inhibition $(\%)=$ [percentage haemolysis by mannan - percent age haemolysis by (mannan + inhibitor) $] \times 100$, divided by percentage haemolysis by mannan.

$\dagger$ Inhibition activity of PLP at $1.0 \mathrm{mM}$ was not examined, because of haemolysis by PLP.

The haemolytic activity of mannan was inhibited by the addition of DIDS (Table 1). A family of stilbene disulfonate derivatives, DIDS, SITS and $\mathrm{BS}^{3}$, inhibits anion transport by binding covalently or noncovalently to the Lys-539 or Lys-542 of band 3 protein (Yamaguchi et al., 1995). PLP reacts with Lys- 851 in band 3 protein, and is an inhibitor of band 3-mediated anion exchange (Okubo et al., 1994). The stilbene disulfonate derivatives inhibited the haemolysis, but PLP did not (Table 1). These results suggest that the binding of the mannan to RBCs was mediated by Lys-539 or Lys-542 in band 3 protein.

\section{DISCUSSION}

Some pathogenic micro-organisms secrete haemolytic factors in order to obtain haemoglobin or haemin as a source of iron (Belanger et al., 1995; Lewis \& Dyer, 1995). We previously reported that haemoglobin utilization by C. albicans was related to a morphological change (Watanabe et al., 1997). A complement-mediated haemolysis induced by secretion from $C$. albicans has been observed (Manns et al., 1994), but the secretion of a haemolytic factor by C. albicans was not reported. In the present paper, we have demonstrated the secretion of a haemolytic factor by C. albicans and characterized this factor.

The disruption of RBCs was significantly promoted by the addition of C. albicans culture supernatant (Fig. 1), indicating that a haemolytic factor was released from $C$. albicans. Since C. albicans secretes an aspartyl protease for invasion into the host (Colina et al., 1996; Zink et al., 1996), such an enzyme has been suggested as the cause of the haemolysis. However, the addition of pepstatin $\mathrm{A}$, an aspartyl protease inhibitor, or treatment 
at $100{ }^{\circ} \mathrm{C}$ for $10 \mathrm{~min}$ did not affect the haemolytic activity (data not shown). Thus, we suggest that the haemolytic factor is not enzymic. The haemolytic activity was associated with a sugar-rich fraction of approximately $200 \mathrm{kDa}$. This fraction also reacted with Con $\mathrm{A}$ and FAb 1 (Fig. 2). These results demonstrate that the haemolytic activity was probably caused by a mannoprotein. When the sugar moiety of the mannoprotein was disrupted by periodate oxidation, the haemolytic activity was lost. This suggests that the sugar moiety of the mannoprotein is important for binding to $\mathrm{RBCs}$ and/or for inducing haemolysis. Structural studies indicated that the haemolytic fraction contained sugar residues typical of cell-wall mannans, and purified bulk mannan also showed haemolytic activity. Both mannan binding to RBCs and the haemolytic activity of mannan were strongly inhibited by treatment with DIDS (Fig. 4, Table 1). As DIDS is an anion-transport inhibitor which binds to band 3 protein, band 3 protein might be involved in the binding of, and haemolysis by, mannan. The binding of mannan to RBCs was inhibited by DIDS, indicating that DIDS masked the mannan-binding site of the band 3 protein. A family of stilbene disulfonate derivatives, DIDS, SITS and $\mathrm{BS}^{3}$, which inhibit anion transport by binding covalently or noncovalently to Lys539 or Lys-542 of band 3 protein (Yamaguchi et al., 1995), inhibited the haemolysis (Table 1). Thus, it was suggested that the mannan bound to band 3 protein on RBCs, and that Lys-539 or Lys- 542 of band 3 protein might be an important site for the binding of mannan. The results with PLP supported this conclusion. Since band 3 protein catalyses anion exchange and seems to be associated with spectrin via ankyrin (Yamaguchi et al, 1995), we suggest that the mannan destabilizes the RBC membrane through the function of band 3 protein.

As haemolytic activity was detected in the culture supernatant of C. albicans in vitro, some mannoprotein may be produced at local sites in vivo. However, large amounts of mannoprotein are not detected in patients with candidiasis. Although systemic haemolysis may not be caused by the mannoprotein, haemolysis around infected sites may enhance the growth of C. albicans because haemoglobin is an important factor for Candida growth in the host.

\section{REFERENCES}

Ataoglu, H., Zueco, J. \& Sentandreu, R. (1993). Characterization of epitopes recognized by Candida factor 1 and 9 antisera by use of Saccharomyces cerevisiae mnn mutants. Infect Immun 61, 3313-3317.

Belanger, M., Begin, C. \& Jacques, M. (1995). Lipopolysaccharides of Actinobacillus pleuropneumoniae bind pig hemoglobin. Infect Immun 63, 656-662.

Blasi, E., Pitzurra, L., Bartoli, A., Puliti, M. \& Bistoni, F. (1994). Tumor necrosis factor as an autocrine and paracrine signal controlling the macrophage secretory response to Candida albicans. Infect Immun 62, 1199-1206.

Cameron, B. J. \& Douglas, L. J. (1996). Blood group glycolipids as epithelial cell receptors for Candida albicans. Infect Immun 64, 891-896.
Colina, A., Aumont, F., Deslauriers, N., Belhumeur, P. \& Repentigny, L. (1996). Evidence for degradation of gastrointestinal mucin by Candida albicans secretory aspartyl protease. Infect Immun 64, 4514-4519.

England, B. J., Gunn, R. B. \& Steck, T. L. (1980). An immunological study of band 3 , the anion transport protein of the human red blood cell membrane. Biochim Biophys Acta 623, 171-182.

Fallon, K., Bausch, K., Noonan, J., Huguenel, E. \& Tamburini, P. (1997). Role of aspartic protease in disseminated Candida albicans infection in mice. Infect Immun 65, 551-556.

Henderson, D. P. \& Payne, S. M. (1994). Vibrio cholerae iron transport systems: roles of heme and siderophore iron transport in virulence and identification of a gene associated with multiple iron transport system. Infect Immun 62, 5120-5125.

Ibrahim, A. S., Mirbod, F., Filler, S. G., Banno, Y., Cole, G. T., Kitajima, Y., Edwards, J. E., Jr, Nozawa, Y. \& Ghannoum, M. A. (1995). Evidence implicating phospholipase as a virulence factor of Candida albicans. Infect Immun 63, 1993-1998.

Kobayashi, H., Takaku, M., Nishidate, Y., Takahashi, S., Takikawa, M., Shibata, N. \& Suzuki, S. (1992). Structure of the D-mannan of the pathogenic yeast, Candida stellatoidea ATCC 20408 (Type II) strain, in comparison with that of C. stellatoidea ATCC 36232 (Type I) strain. Carbohydr Res 231, 105-116.

Law, D. \& Kelly, J. (1995). Use of heme and hemoglobin by Escherichia coli $\mathrm{O} 157$ and other shiga-like-toxin-producing E. coli serogroups. Infect Immun 63, 700-702.

Lewis, L. A. \& Dyer, D.W. (1995). Identification of an ironregulated outer membrane protein of Neisseria meningitidis involved in the utilization of hemoglobin complexed to haptoglobin. J Bacteriol 177, 1299-1306.

Manns, J. M., Mosser, D. M. \& Buckley, H. R. (1994). Production of a hemolytic factor by Candida albicans. Infect Immun $\mathbf{6 2}$, 5154-5156.

Mikami, T., Suzuki, S., Schuerch, C. \& Suzuki, M. (1986). Enzymelinked immunosorbent assay for several mannans. Chem Pharm Bull 34, 3933-3935.

Okubo, K., Kang, D., Hamasaki, N. \& Jennings, M. L. (1994). Red blood cell band 3: lysine 539 and lysine 851 react with the same H2DIDS (4, $4^{\prime}$-diisothiocyanodihydrostilbene-2,2' -disulfonic acid) molecule. J Biol Chem 269, 1918-1926.

Otto, B. R., Verweij-van Vught, A. M. J. J. \& Maclaren, D. M. (1992). Transferrins and heme-compounds as iron source for pathogenic bacteria. Crit Rev Microbiol 18, 217-233.

Pendrak, M. L. \& Klotz, S.A. (1995). Adherence of Candida albicans to host cells. FEMS Microbiol Lett 129, 103-114.

Pfaller, M. A., Grant, C., Morthland, M. \& Rhine-Chalberg, J. (1994). Comparative evaluation of alternative methods for broth dilution susceptibility testing of fluconazole against Candida albicans. J Clin Microbiol 32, 506-509.

Sawyer, R. T., Garner, R. E. \& Hudson, J. A. (1992). Arg-Gly-Asp (RGD) peptides alter hepatic killing of Candida albicans in the isolated perfused mouse liver model. Infect Immun 60, 213-218.

Shibata, N., Fukasawa, S., Kobayashi, H., Tojo, M., Yonezu, T., Ambo, A., Ohkubo, Y. \& Suzuki, S. (1989). Structural analysis of phospho-D-mannan-protein complexes isolated from yeast and mold form cells of Candida albicans NIH A-207 serotype A strain. Carbohydr Res 187, 239-253.

Shibata, N., Kojima, C., Satoh, Y., Satoh, R., Suzuki, A., Kobayashi, H. \& Suzuki, S. (1993). Structural study of a cell-wall mannan of Saccharomyces kluyveri IFO 1685 strain - presence of a branched side chain and $\beta$-1,2-linkage. Eur J Biochem 217, 1-12.

Shibata, N., Ikuta, K., Imai, T. \& 7 other authors (1995). Existence 
of branched side chains in the cell wall mannan of pathogenic yeast, Candida albicans. J Biol Chem 270, 1113-1122.

Suzuki, M., Mikami, T., Matsumoto, T. \& Suzuki, S. (1977). Preparation and antitumor activity of O-palmitoyldextran phosphates, O-palmitoyldextrans, and dextran phosphate. Carbohydr Res 53, 223-229.

Tojo, M., Shibata, N., Osanai, T., Mikami, T., Suzuki, M. \& Suzuki, S. (1991). Sandwich enzyme-linked immunosorbent assay of Dmannans of Candida albicans NIH A-207 and NIH B-792 strains using concanavalin $\mathrm{A}$ and polyclonal rabbit anti-C. albicans antisera. Carbohydr Res 213, 325-330.

Watanabe, T., Tanaka, H., Nakao, N., Mikami, T. \& Matsumoto, T.
(1997). Hemoglobin is utilized by Candida albicans in the hyphal form but not yeast form. Biochem Biophys Res Commun 232, 350-353.

Yamaguchi, T., Matsumoto, M. \& Kimoto, E. (1995). Effects of anion transport inhibitors on hemolysis of human erythrocytes under hydrostatic pressure. J. Biochem 118, 760-764.

Zink, S., Naß, T., Rosen, P. \& Ernst, J. F. (1996). Migration of the fungal pathogen Candida albicans across endothelial monolayers. Infect Immun 64, 5085-5091.

Received 29 June 1998; revised 9 October 1998; accepted 18 November 1998. 